\title{
An Estimation of the Association of Postpartum Depression with Mizaj (Temperament) in Postnatal Women: A Cross-sectional Study
}

Farheen Zaidi ${ }^{1}$, Rubi Anjum ${ }^{1}$

${ }^{1}$ Department of Tahaffuzi-wa-Samaji-Tibb (PSM) Faculty of Medicine (Unani), Jamia Hamdard, New Delhi, India.

\section{ABSTRACT}

Postpartum depression (PPD) is a major public health problem similar to the depression at other times. It is frequently seen in postnatal women of all cultures including the developed (10\%-15\%) and the developing countries (11\%-48\%). The Unani and modern fiction mutually proposes the role of pregnancy and childbirth in the development of this psychiatric disorder: Moreover, the former system also suggests the role of mizaj (temperament) in the development of this disarray.

To study the association of PPD with the mizaj (temperament) of postnatal women at their 6 weeks of delivery in a tertiary hospital of New Delhi.

A total of 231 postnatal women were interviewed using the Edinburgh Postnatal Depression Scale (EPDS) at their 6 weeks of delivery. The mizaj (temperament) of each participant was measured with the assistance of Ajnas-e-Ashra.

Twenty-eight out of 231 postnatal women scored $\geq 10$ on the EPDS. PPD was seen in women of all 4 temperaments, but on comparing the 2 groups (depressed and nondepressed) on the basis of mizaj of women, no statistically significant association was seen (P value $>0.05)$. Therefore, the result suggested no significant association of PPD with the temperament of postnatal women.

PPD is the common mental disarray that can be seen in women of all temperaments. Thus, screening of PPD should be taken into account among all women as the routine practice so that the hazards of PPD can be prevented.

Key words: Postnatal women, postpartum depression, temperament

\section{INTRODUCTION}

Although pregnancy and childbirth have embodied the time of contentment and pleasure in every woman's life, according to the physicians of ancient (Unani) and recent times they also contribute to the substantial threat to the mental health of women (1-5). The expression postpartum depression is merely used for a nonpsychotic depressive illness of mild-tomoderate severity belonging or extending into the first postnatal year (6-13) and generally observed within 4-6 or 6-8 weeks of delivery $(3,14)$. It is also defined as the depression similar to atypical depression at other times of the major public health problem seen in both developed (10\%-15\%) and developing countries $(11 \%-42 \%)(15,16)$.

PPD is not a new entity; it is as old as medicine itself since it was first discussed by Hippocrates (460-370 BC) under the terminology called melancholia (17). Melancholia is the denotation of fassad-e-fikr, that is, disturbance in the intellect of an individual because of reallocation in the customary quality and quantity of sawda (black bile) (18). In the present scenario however, it is represented as one of the severe forms of depression (19). 
Unani physicians of ancient times such as Zakaria Razi, RabbanTabri, Ibn-e-Sina, N. Samarqandi, and M.H. Qarshi mutually recognized the deleterious effects of infiyalat-e-nafsaniyah (emotions) such as grief, anger, happiness, regret, love, and so forth, on human psyche, especially among women at the times of their pregnancy, childbirth, and puerperium. Moreover, they also gave the concept of other psychiatric disorders among postnatal women such as puerperal mania and puerperal dementia as negative consequences of childbirth $(2,4,20)$.

According to the concept of Unani system of medicine, mizaj (temperament) of an individual acts as an imperative risk factor for various disorders including the psychiatric disarray such as depression or melancholia. According to the Unani scholars, among the four temperaments, mizaj-e-saudawi (melancholic temperament) predisposes an individual to develop the depressive symptomatology most (21). However, it is thought that any of the four humors can develop such an illness (22). This study is therefore intended to determine the association of PPD with the temperament of postnatal women.

\section{MATERIAL AND METHODS}

\section{Study design and setting}

It is a cross-sectional study that was undertaken among the postpartum women who received postnatal care at the $\mathrm{HAH}$ Centenary Hospital, New Delhi. The hospital provides routine care, obstetric services, and postnatal care for mothers and childhood immunization.

\section{Selection of Subjects}

Eligible participants included all the postnatal women at their 6 weeks of delivery who gave informed consent to participate in the study. However, women with a previous history of psychiatric illness and any other chronic disorders such as diabetes and hypothyroidism were excluded from the study.

\section{Method of study}

This study was performed in the antenatal clinic of Hakeem Abdul Hameed Centenary Hospital. An informed consent from each eligible participant was taken. Consequently, 231 postnatal women at 6 weeks of their delivery were screened for PPD. Nevertheless, the mizaj of each postnatal woman was also estimated to assess whether it has any significant role as the risk factor of PPD or not.

Measures

Screening of PPD among the postnatal women was done with the assistance of Edinburgh Postnatal Depression Scale (EPDS). EPDS is a standardized tool based on 10 questions recommended to screen women in the antenatal and postpartum periods. In the present study, the Hindi version of EPDS was used in which a cut score of $\geq 10$ indicated the presence of depression. The calculated Cochrane's alpha value was within the range of 0.814-0.844, which was quite reliable.

The classical literature indicates a set of 10 parameters called Ajnas-e-Ashra on the basis of which mizaj of an individual can be identified. These parameters are complexion, built, touch, hair, movements, diet, weather, sleep, pulse, and emotions. Here also Ajnas-e-Ashra was taken into consideration for assessing mizaj of each postnatal woman.

Data Analysis

The data were analyzed using Microsoft Excel and SPSS version 17. The sample was categorized on the basis of the presence or absence of PPD in the two groups: depressive and nondepressive postnatal women. Afterward, using the chi-square test, the two groups were compared on the basis of mizaj of the postnatal women.

\section{RESULTS}

Out of 231 postnatal women, a majority (50.2\%) belonged to the age group of 26-29 years, were living in joint families (63.6\%), and were following Hinduism (59.3\%). Also, among all postnatal women, 99 (42.9\%) had mizaj-e-balghami (phlegmatic temperament), 63 (27.3\%) had mizaj-e-safrawi (biliary temperament), and 38 (16.5\%) and 31 (13.4\%) postnatal women had mizaj-e-saudawi (melancholic temperament) and mizaj-e-damwi (sanguineous temperament), respectively. Moreover, out of 231 postnatal women, 28 (12.12\%) were found to have depression at their 6 weeks of delivery (PPD), on the basis of which 2 groups of postnatal women were formed as depressed and nondepressed groups comprising 28 and 203 postnatal women, respectively (Table 1). 
TABLE 1: Comparison between depressed and nondepressed groups of postnatal women on the basis of their mizaj (temperament).

\begin{tabular}{|c|c|c|c|c|c|c|c|c|c|}
\hline \multirow{3}{*}{ Mizaj } & \multicolumn{4}{|c|}{ Group } & & & \multirow[b]{2}{*}{$\chi^{2}$} & \multirow[b]{2}{*}{ Df } & \multirow[b]{2}{*}{$P$ value } \\
\hline & \multicolumn{2}{|c|}{$\begin{array}{l}\text { Depressed } \\
(\mathrm{N}=28)\end{array}$} & \multicolumn{2}{|c|}{$\begin{array}{l}\text { Nondepressed } \\
(\mathrm{N}=203)\end{array}$} & \multicolumn{2}{|c|}{$\begin{array}{l}\text { Total } \\
(\mathrm{N}=231)\end{array}$} & & & \\
\hline & (n) & $(\%)$ & (n) & $(\%)$ & (n) & $(\%)$ & 2.304 & 3 & 0.505 \\
\hline Sanguineous & 3 & 10.7 & 28 & 13.8 & 31 & 13.4 & & & \\
\hline Phlegmatic & 9 & 32.1 & 90 & 44.3 & 99 & 42.9 & & & \\
\hline Bilious & 10 & 35.7 & 53 & 26.1 & 63 & 27.3 & & & \\
\hline Melancholic & 6 & 21.4 & 32 & 15.8 & 38 & 16.5 & & & \\
\hline
\end{tabular}

\section{DISCUSSION}

According to the classical Unani literature, depression is seen in all four varieties of mizaj, but the persons with mizaj-e-saudawi (melancholic temperament) are supposed to be more prone to get affected with this disarray21,22. In the present study, the first assumption was found to be precise, as depression was seen in all four varieties of mizaj in different percentages (Table 1). Nevertheless, Table 1, shows that the percentage of depressed postnatal women from mizaj-e-saudawi (21.4\%) was lesser than that of women with mizaj-e-safrawi (35.7\%) and mizaj-e-balghami(32.1\%), and higher than that of women with mizaj-e-damwi (10.7\%). However, among the two groups the percentage of mizaj-e-sawdawi was higher (21.4\%) in the depressed postnatal women than in their counterparts (15.8\%). Similarly, mizaj-e-safrawi had a higher percentage among the depressed postnatal women (35.7\%) than among the nondepressed ones (26.1\%). On the contrary, the percentage of mizaj-e-balghami (44.3\%) and mizaj-e-damwi (10.8\%) was found to be higher among the women of nondepressed group than among the women of depressed group. Yet after the analysis, the difference among the two groups was not found to be statistically significant ( $P>0.05$ ) (Table 1). The findings suggested that PPD had no significant association with the variability of temperament of the postnatal women. Moreover, any temperament could predispose the postnatal women to PPD. The reason for this could be the excessive variation between the percentage of mizajamong the subjects, as the majority (42.9\%) of postnatal women belonged to the mizaj-e-balghami, and the percentage of mizaj-e-saudawi was much lesser (16.5\%). Therefore, an accurate assessment could be done if the subjects from all varieties of temperament were in equal fractions.

\section{CONCLUSION}

PPD is acommon mental disarray among postnatal women, and this should not be undermined as a normal consequence of child birth. Moreover, it can be seen in women of all temperaments. Therefore, screening of PPD should be a routine practice for all postnatal women and should be carried out at all postnatal clinics to prevent hazardous consequences of PPD at an early stage.

\section{ACKNOWLEDGMENT}

The authors would like to thank the Jamia Hamdard Institute where the study was performed.

\section{REFERENCES}

1. Mantle.J, Haslam.J\&Barton.S, Physiotherapy in Obstetrics and Gynaecology, 2nd edition, Bulter Heinemann, Elsevier limited, 2004, pp- 131, 132

2. Qarshi.M.H, 2011, Jami-ul-Hikmat,Ejaz Publishing House, 2011, pp. 349-351, 354-357.

3. Sadock.B.J\&Sadock.V.A, Kalpan's and Sadock's Concise Textbook of Clinical Psychiatry, 3rd Edition, Wolters Kluwer, Lippincott Williams and Wilkins, 2007, pp. 406, 407.

4. Samarqandi.N, Moalijat-Shara-e-Asbab, Urdu Translation by M. Kabeeruddin, IdaraKitab-Us-Shifa, 2009, pp. 84-89, 99, 100, 102, 103, 105, 106.

5. Symonds ME, Symonds IM, Essential Obstetrics and Gynecology, 4th Edition, Churchill Livingstone, 2004, pp. 219-231.

6. Al-Hinai FI, Al-Hinai SS, Prospective Study on Prevalence and Risk Factors of Postpartum Depression in Al-Dakhlyia Governorate in Oman, Oman Medical Journal, 2014, 29(3), 198202.

7. Josefsson A, Postpartum depression- Epidemiological \& biological aspects. Medical dissertation, Linkoping University, Sweden (2003) [Cited on 5 May 2014]. Available from: <http// www.liu.diva-portal.org/smash/get/diva/2:21141/Full> 
8. Lanes A, Kuk JL, Tamim H, Prevalence and characteristics of Postpartum depressive symptomatology among Canadian women: A cross sectional study, BMC Public Health (2011) [cited on 9 May 2014]. Available from: http//: www.biomedcentral. com/1471-2458/11/302

9. NHMRC, (National Health Medical Research Council), Postnatal depression A systematic review of published scientific literature to 1999 (2000) [cited on 4 December 2014]..Available from: <http: www.nhmrc.gov>

10. Nielsen NO, Strøm M, Boyd HA, Andersen EW, Wohlfahrt J, et al, Vitamin D Status during Pregnancy and the Risk of Subsequent Postpartum Depression: A Case-Control Study. PLOS ONE vol. 2013; 8(11). Available from: <http//: www.plosone.org>

11. Robertson E, Grace S, Wallington T, Stewart DE, Antenatal risk factors for postpartum depression: A synthesis of recent literature, General Hospital Psychiatry, 2004; 26(4), 289-295.

12. Verkerk GJM, Denolet J, Guus L, Hack V, VanSon MJM, Pop VJM, Patient preference for counselling predicts postpartum depression: a prospective 1-year follow up study in high-risk women. Journal of Affective Disorders, 2004; 83, pp. 43-48.

13. World Health Organization, Postpartum Depression: An Overview of Treatment and Prevention (2011) [cited on 12.12.14]. Available from: http://www.gfmer.ch/SRHCourse-2011/maternal-health/pdf/Postpartum-depressionCorey-2011.pdf
14. Daftary SN, Chakravarti S, Manual of Obstetrics, 3rd Edition, Elsevier, 1988, pp. 404.

15. Hegde S, Latha KS, Bhat MS, Sharma PSVN, Kamath A, Shetty AK, Postpartum Depression: Prevalence and Associated Factors Among Women in India, Journal of Women's Health Issues and Care, 2012; 1(1).

16. Cunninghum FG, McDonald PC, Gant NF, Leveno KJ, Gilstrap LC, Hankins GDV, Clark SL. Williams Obstetrics, 20th edition, Prentice Hall International, INC, 1997, pp- 1265-1268.

17. Shives.L.R, Basic concepts of Psychiatry- Mental Health and Nursing, 8th Edition, Wolters Kluwer (India) Pvt Ltd., 2012 , pp298, 303, 307, 309.

18. Tabri.A.A.M, Al Moalijat-Al-Buqatiya, Urdu Translation by CCRUM, AYUSH, Ministry of Health and Family Welfare, New Delhi, 1997; 1, pp. 374, 378, 380.

19. Papadakis.M.A\&McPhee.S.J, Current Medical Diagnosis and Treatment, 51st Edition, Lange Medical Books, McGraw Hill, 2012, PP. 1035.

20. Ali A, Eminent Arab-Muslim Medical Scientists, 1st Edition, KitabBhavan, New Delhi, 2001, pp. 12, 23, 33, 91, 92, 98.

21. Khan.A, Haziq, Madina Publishing Company Karachi, 1983, pp46-52.

22. Khan MA, Al Akseer-e-Aazam, Urdu Translation by, M.Kabeeruddin, Ejaz Publishing House, 2010, pp. 118-121. 